\title{
A new form of Miscanthus (Chinese silver grass, Miscanthus sinensis-Andersson) as a promising source of cellulosic biomass
}

\author{
Vladimir K. Shumny, Sergey G. Veprev, Nikolay N. Nechiporenko, Tatiana N. Goryachkovskaya, \\ Nikolay M. Slynko, Nikolay A. Kolchanov, Sergey E. Peltek
}

Siberian Branch of Russian Academy of Science, Institute of Cytology and Genetics, Novosibirsk, Russia.

Email:peltek@bionet.nsc.ru

Received 28 April 2010; revised 5 June 2010; accepted 7 June 2010.

\begin{abstract}
The Far East population of Miscanthus sinensis (Andersson) was introduced into the West Siberia conditions. There was distinguished a form with a modified structure of the rootage which forms long shoots with leader buds and rapidly colonizes soil, thus forming a continuous and flat (without tussocks) plantation of miscanthus. It is shown that using usual agrotechnologies, it is possible to obtain 10-15 tons of dry biomass of high quality cellulose (about $40 \%$ ) per ha/year.
\end{abstract}

Keywords: Cellulose; Lignin; Biomass; Cellulosic Biomass; Miscanthus sinensis; Vegetative Reproduction of Plants

\section{INTRODUCTION}

At present, only two sources of cellulose: cotton and wood biomass are of industrial importance. Cotton represents almost pure cellulose and does not require a complicated processing. Wood mass contains $40-44 \%$ of cellulose [1].

Plants with relatively a low content of lignin, in which the main mass of structural elements represents cellulose, can be used as an alternative cellulosic biomass. Introduction of plants species into the culture, yielding a high harvest of biomass with a high content of cellulose, cultivated by conventional agricultural methods can be quite a promising way to involve the new sources of high quality cellulose for the multipurpose use. The research into evaluation of plants with high content of cellulose as promising raw sources for chemical industry and power production is carried out in the world [2].

In the Interactive European Network for Industrial Crops and their Application (IENICA) there is infor- mation about more than 90 kinds and species of promising plants that are studied as raw materials sources for chemical, fuel and power industries [3]. All these plants are herbs which are suitable for cultivation by generally accepted methods of agricultural production.

A special attention to such type of plants is quite justified, as the majority of them reproduces by seeds and can be cultivated in traditional agricultural regions and possess a high rate of accumulation cellulosic biomass in stalks. Among them there are well-known kinds: wheat, oats, corn, nettle, hemp, sunflower, flax etc. Currently the list of the kinds-candidates is actively supplemented.

One of the non-conventional species is Miscanthus sinensis (Andersson) to be called the Elephant grass. The plants are really giant of 3 meters high. Miscanthus is a sort of perennial herbs belonging to the bluegrass (Poa) family. More than twenty species belong to class of Miscanthus and they are widespread from the tropical and South Africa to the East and South East Asia. In Russia, in the Far East there are 3 kinds of miscanthus: Miscanthus sacchariflorus, Miscanthus purpurascens, Miscanthus sinensis [4].

Systematization of the genus in question is not steady and it is constantly exposed to revision.

Definition of chromosomal numbers of various kinds does not simplify the situation: four from the fourteen kinds that were sufficiently studied, represent anisoploid populations (a plants mixture of various ploidy, probably, from diploids-38 chromosomes to hexaploids -114 chromosomes). There was fixed a various number of chromosomes in somatic cells at three varieties, including Miscanthus sinensis (Andersson): 35, 36, 38, 40, 41, 42, 57 [5].

Nowadays miscanthus is widespread as an ornamental plant. There was created a great number of forms and varieties of miscanthus, some of them are exotic 
enough, for example, the species with striped leaves. In most cases miscanthus is attractive as a part of green hedges, and its panicle as an element of winter bouquets. The miscanthus is widely considered as a raw source of cellulose because of its high productivity of dry biomass, drought-tolerance and frost-resistance. Actually, according to the IENICA CROPS DATABASE (for example, for the giganteus species, used in Europe) its production is 11.7-25.3 tons of dry biomass per ha/year. In Denmark, the gathering of 44 tons of dry biomass per ha/year was fixed. The results of defining the chemical composition confirm the content of cellulose within $44 \%$, lignin- $17 \%$, hemicellulose$24 \%[3,6]$.

\section{RESULTS AND DISSCUSSION}

\subsection{Reproduction and Cultivation of Miscanthus sinensis}

By now, the general principles of reproduction and cultivation of miscanthus have been well developed for the conditions of Europe and the USA. Its existing species do not reproduce by seeds, their reproduction being possible only by rhizomes. Rhizomes are short enough $(5-10 \mathrm{~cm})$ and are formed during vegetation. They pass the winter and flush in spring. As a result there is a slow colonization of the soil space with formation of strongly rampant hummocks. Transplanting is carried out in spring with separate short rhizomes, usually placing them in rows with row-spacing of $60-75 \mathrm{~cm}$. Miscanthus is unpretentious to a soil, but it is necessary to enrich it with a full norm of mineral fertilizers. The maximum productivity of planting is reached for the $3 \mathrm{~d}$ or the 4 th year, whereupon the annual biomass crop is saved up to 15-20 years [3].

\subsection{A New form of Miscanthus sinensis (Anderson)}

Availability of this species as a source of cellulose has stimulated the search for the new forms appropriate for agroindustrial technologies in the conditions of West Siberia.

More than 10 years ago an expedition from the Institute of Cytology and Genetics of the Siberian Branch of the Russian Academy of Sciences, supervised by academician V. K. Shumny (Dr. V. A. Godovikova's team) worked in the Far East with participation of academician P. G. Gorovoy, a well-known botanist from the Far-East Branch of the Russian Academy of Sciences investigated populations of miscanthus plants on the Pacific ocean coast. The first samples of these populations were brought to Novosibirsk. They were reproduced and the population-genetic and selection research into this kind and replenishment of the collection of the Far East samples were begun at the Institute of Cytology and genetics of the Siberian Branch of the Russian Academy of Sciences.

As a result, there was obtained an unusual form of miscanthus with very long rhizomes which quickly colonized the soil and thus there was created a continuous and flat plantation of miscanthus.

In three years miscanthus plantation turned into 2$2.5 \mathrm{~m}$ tall thickets when planting such long rhizomes in furrows with row-spacings of $60 \mathrm{~cm}$ (Figure 1).

Next years the thickness of stalks was stabilized at a level of 200-220 per sq.m. In the soil rhizomes have formed a solid net at a depth of $5-20 \mathrm{~cm}$ and their length was $60-65 \mathrm{~m} / \mathrm{m}^{2}$. Further study of the rhizomes formation has shown that they grow up to one meter and higher during the season, in addition, the buds, which provide a continuous regrowth of new shoots
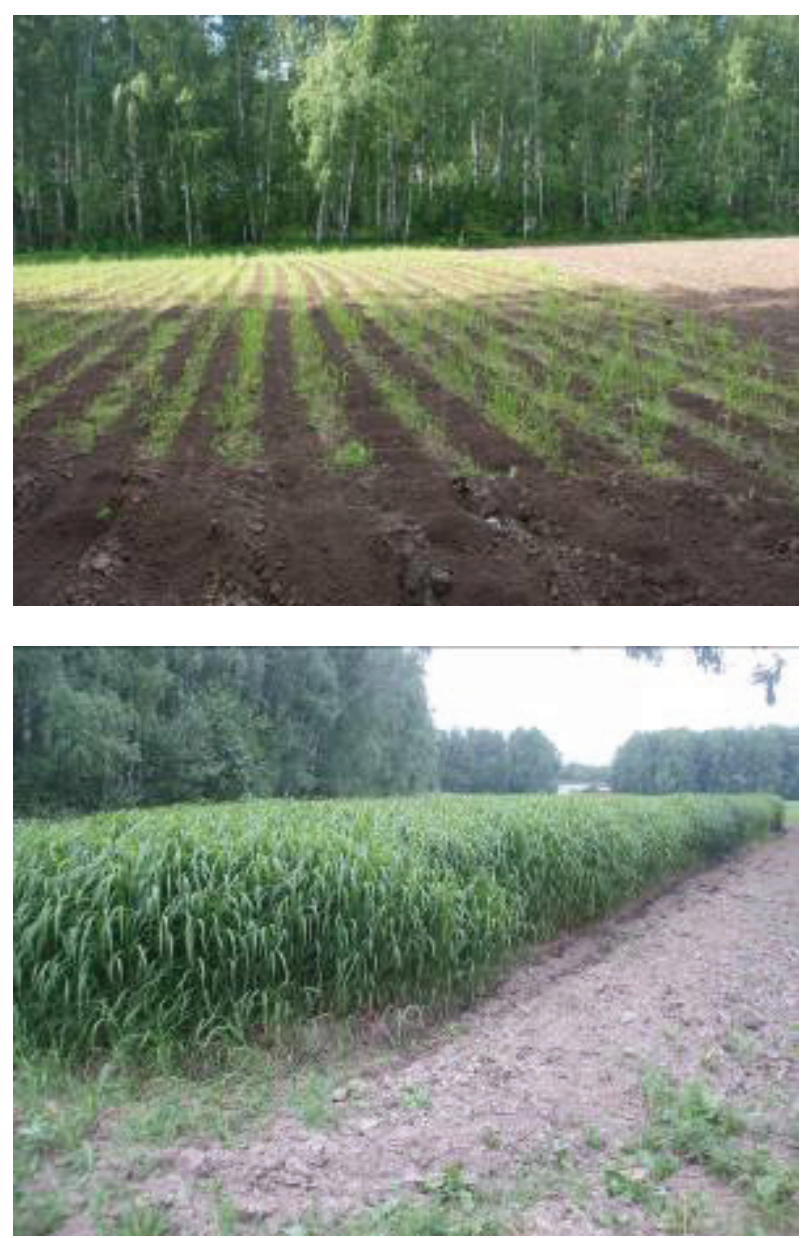

Figure 1. On the top: The June shoots of miscanthus after landing in the second half of May; on the bottom: an eight-year plantation of miscanthus in August (Novosibirsk, 2008). 
appear on them. Such a way of reproduction allows an essential simplification of plants transplanting: firstly, rhizomes are easy to separate from each other; secondly, they are easily placed in furrows by continuous tape.

To analyze the production of experimental plantations, the trial hay harvests were done. The straw exit was on the average 10-15 tons per hectare during years. A high quality straw with the content of cellulose, suitable for the multi-purpose use was about $40 \%$. The characteristics obtained are comparable with the data from IENICA-CROPS DATABASE for the European species of miscanthus (see above), however they were obtained for conditions of the south of West Siberia in a shorter vegetative period and at rewinterings in a sharply continental climate.

Moreover, a plantation with a continuous application of plants allows one to carry out agrotechnical actions only during the early-spring period (May) and to introduce fertilizers with a subsequent soil loosening.

Studies on the biology of the new form of miscanthus have shown that it is possible to create an agroindustrial technology of cellulose biomass as a promising source of cellulose of the multi-purpose use. Clearly it is necessary to evaluate the efficiency of an agroindustrial way of manufacturing the cellulose biomass comparatively with a traditional cutting down of woods.

\subsection{Efficiency of Agroindustrial Technology of Cellulose Production}

We have shown that the new form of miscanthus and the proposed technology of its cultivation are capable of yielding a harvest of dry biomass (cellulosic biomass) at a level of 10-15 t/ha/year in the West Siberia conditions. For the formation of a long-term steadily functioning plantation (for 15-20 years) two-three years are needed. Forests accumulate a biomass during decades and 100-140 years is a normal age for a mature forest. It is easy to compare the efficiency of accumulation of dry biomass of woods of different breeds and of the miscanthus agroindustrial cultivation as an industrial crop $[7,8]$.

Calculations of such a comparison are presented in Table 1 and on Figure 2. The production of wood breeds is taken for forests of the growth class Ia, i.e. the best ones [9]. The efficiency of accumulation of dry biomass by miscanthus plantation is calculated for a twenty years cycle, the mowing off beginning from the second year after landing and this is annually done.

After 20 years of vegetation a plantation is destroyed and a new one is made. Calculation is carried out based on a minimum efficiency of miscanthus in the conditions of West Siberia (10 t/ha/year), starting with the third year of its planting out. The production of the
Table 1. Biomass accumulation in miscanthus manufacturing in comparison with the major tree species of the growth class Ia.

\begin{tabular}{lllll}
\hline year & $\begin{array}{l}\text { Miscanthus } \\
\text { t/ha }\end{array}$ & $\begin{array}{l}\text { Pine } \\
\text { t/ha }\end{array}$ & $\begin{array}{l}\text { Birch } \\
\text { t/ha }\end{array}$ & $\begin{array}{l}\text { Aspen } \\
\text { t/ha }\end{array}$ \\
\hline 5 & 35 & & & \\
10 & 85 & & 25 & 25 \\
20 & 185 & 56 & 68 & 54 \\
30 & 270 & 112 & 112 & 84 \\
40 & 370 & 170 & 152 & 116 \\
50 & 455 & 224 & 187 & 148 \\
60 & 555 & 269 & 215 & 175 \\
70 & 640 & 308 & 239 & 196 \\
80 & 740 & 340 & 259 & 212 \\
90 & 825 & 368 & 275 & 223 \\
100 & 925 & 392 & 287 & 229 \\
\hline
\end{tabular}

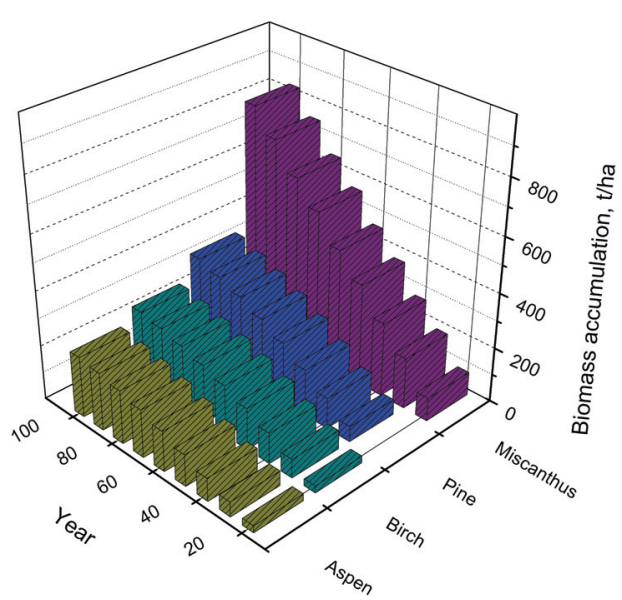

Figure 2. Biomass accumulation in Miscanthus manufacturing in comparison with the major tree species of the growth class Ia.

second year plantation is generally accepted as 5 $\mathrm{t} / \mathrm{ha} /$ year. Thus, in 20 years, the production of Miscanthus plantation will make 185 tons per hectare. The period of hundred years, presented in Table 1, corresponds to five full agrotechnical cycles of miscanthus.

From Table 1 it follows that miscanthus plantations essentially surpass the best forests of a temperate Euroasian zone in efficiency of biomass accumulation.

It is possible to calculate a mid-annual increment of biomass according to the accepted plan of miscanthus cultivation for the comparison with the referenced data for the forests of the growth class Ia [7] (Table 2).

As a whole in Russia the average store of wood biomass per hectare in the ripe and overripe forests to be exploited fluctuates from 75 up to 175 tons, but it is necessary to take into account that more than one half of all the forests of Russia grows in permafrost soils of Siberia and Far East. This causes their low productivity. Only $55 \%$ of the areas of these forests are of interest 
Table 2. A mid-annual increment of biomass in miscanthus manufacturing and in the forests of the growth class Ia.

\begin{tabular}{lllll}
\hline $\begin{array}{l}\text { Miscanthus } \\
\mathrm{t} / \mathrm{ha}\end{array}$ & $\begin{array}{l}\text { Pine } \\
\mathrm{t} / \mathrm{ha}\end{array}$ & $\begin{array}{l}\text { Birch } \\
\mathrm{t} / \mathrm{ha}\end{array}$ & $\begin{array}{l}\text { Aspen } \\
\mathrm{t} / \mathrm{ha}\end{array}$ & $\begin{array}{l}\text { The average in Russia* } \\
\mathrm{t} / \mathrm{ha}\end{array}$ \\
\hline 9,3 & 3,6 & 3,4 & 2,7 & 0,6 \\
\hline
\end{tabular}

* Mid-annual increment of wood in the forests of Russia covered with vegetation [10]

for exploitation purposes. From these 55\% many large forests are remote and unavailable [10].

The agroindustrial manufacturing technology of cellulosic biomass has undoubted social benefits.

Miscanthus is an industrial crop, and there is no necessity to use fertile arable lands for its plantations. Unpretentiousness to soils is its clear advantage. Only in the Novosibirsk region, more than one million of hectares were removed from a crop rotation for the last few years. These soils do not justify themselves when farming grains. In the presence of mineral fertilizers it appears possible to successfully develop miscanthus production. Thus, it is possible to make a conclusion that organization of agroindustrial manufacturing cellulosic biomass based on the technology of farming industrial crop - miscanthus as an additional source of high-quality cellulose seems quite promising.

Undoubtedless, a variety of similar industrial crops should be increased. It is necessary to search and to study non-conventional kinds for agriculture aimed at working out the technologies of their farming and processing.

The research into miscanthus population that was carried out in the Novosibirsk region conditions allows us to draw the following conclusions:

1) The population possesses a high frost-resistance in conditions of West Siberia, unlike the kinds of miscanthus used in the European countries.

2) Miscanthus is a long-term cereal and in three years of its cultivation, can annually (during 20 years) produce 10-15 $\mathrm{t} / \mathrm{ha}$ of dry biomass on one field that corresponds to 4-6 t/ha of pure high-quality cellulose.

\section{ACKNOWLEDGEMENTS}

This work was done within the framework of the Interdisciplinary Integration Project of the Siberian Branch of the Russian Academy of Science № 73 .

\section{REFERENCES}

[1] Chemical Encyclopedia. http://www.chemport.ru/chemical_encyclopedia

[2] Heaton, E.A., Dohleman, F.G. and Long, S.P. (2008) Meeting US biofuel goals with less land: The potential of Miscanthus. Global Change Biology, 14(9), 2000-2014.

[3] Interactive European Network for Industrial Crops and their Application. http://www.ienica.net/cropsdatabase.htm

[4] The Open Illustrated Atlas of Vascular Plants of Russia and the Neighboring Countries. http://www.plantarium. ru/page/view/item/41884.html

[5] Fedorov, A.A. (Ed.) (1969) Chromosomal numbers of flowering plants. Academy of Sciences of the USSR, the Komarov V.L. Botanical Institute, Nauka, Leningrad.

[6] Dohleman, F.G. and Long, S.P. (2009) More productive than maize in the midwest: How does miscanthus do it? Plant Physiology, 150(4), 2104-2115.

[7] Sanderson, M.A. and Adler, P.R. (2008) Perennial forages as second generation bioenergy crops. International Journal of Molecular Sciences, 9(5), 768-788.

[8] Henry, R.J. (2010) Evaluation of plant biomass resources available for replacement of fossil oil. Plant Biotechnology Journal, 8(3), 288-293.

[9] (1954) Reference-Book for Forestry Worker izd. AS BSSR, Minsk.

[10] (2006) Forests of Russia 2005. Russian Forestry Newspaper, 10, 138-140. 